\title{
Impacts of accidents involving shopping and restocking vehicles on an urban road network
}

\author{
F. Russo ${ }^{1} \&$ A. Comi ${ }^{2}$ \\ ${ }^{I}$ DIIES - Dipartimento di ingegneria dell'Informazione, \\ delle Infrastrutture e dell'Energia Sostenibile, \\ Università degli Studi Mediterranea di Reggio Calabria, Italy \\ ${ }^{2}$ Department of Enterprise Engineering, "Tor Vergata" \\ University of Rome, Italy
}

\begin{abstract}
The paper, within the field of city sustainability, points out the road safety that can have impacts on both social and economic sustainability spheres. In particular, the methods and models for aggregate and disaggregate analysis of road safety are reviewed and the contribution of shopping and restocking vehicles is investigated.
\end{abstract}

Keywords: city sustainability, road accidents, urban freight transport impacts, shopping and restocking vehicles, safety.

\section{Introduction}

On a global level, there is a worldwide focus on sustainability. Sustainability requires that development should allow response to present needs of the human population without impairing the capacity of future generations to satisfy their own needs [1]. In this definition, Economy, Environment and Social are the objectives to which the different strategies at both urban and national level have to be addressed.

Economic sustainability, focusing particularly on efficiency and effectiveness, may be expressed in specific objectives ranging from the reduction of costs incurred by the user and of service production costs, with an increase in production efficiency and product effectiveness, to improvement in the quality of (transport and logistics) services and performance, and to liberalization and regulatory processes which may become an instrument of such sustainability. It 
is necessary to adopt measures to improve economic and environmental performance for all transportation modes, while in urban areas logistical processes need to be redefined.

Environmental sustainability lies at the core of the debate on an international scale. The main issues are those in the road map of the Bali Conference and the Cancun Agreement, which decide what route to follow after the Kyoto protocol. Development of a green economy is beginning to emerge, from the historical Earth Summit of Rio in 1992 to the UN Conference of Rio in 2012. Many steps have been taken in general awareness, even if political responses are more difficult to obtain. The issues concern: an increase in energy efficiency and ecologically compatible fuel; a reduction in pollution produced by the transport system with particular reference to air quality in urban and metropolitan areas; a reduction in visual intrusion and noise levels in urban and non-urban areas.

Social sustainability is structured into different specific objectives. The most important comprise aspects of safety and security, with problems connected to the various areas of risk (including food).

Analyses of road safety involving goods vehicles traditionally focus only on restocking flows, i.e. freight vehicle flows from warehouse/distribution centres to trade or service establishments (e.g. shops, food-and-drink outlets, service activities), and usually neglect private flows due to shopping. But according to some statistics revealed in European cities [2], the shopping flows (i.e. end consumers' movements) represent between $45 \%$ and $55 \%$ of the total goods traffic. Besides, end-consumer choices in relation to type of purchasing undoubtedly influence freight distribution flows: the characteristics of the restocking process are strictly related to the type of retail activities to be restocked in terms of delivery size, delivery frequency, freight vehicle type and so on. Furthermore, end-consumer shopping choices depend on the commercial supply with respect to residence and on end-consumer behaviour, which in turn depends on some characteristics such as age, income, family dimension and lifestyle.

Based on these statements, the paper discusses specific challenges of shopping and restocking vehicles according to road safety (section 2) and recalls methods of studying road accidents (section 3 ). Then, a general modelling framework for disaggregate road safety assessment (section 4) is described. Finally, some conclusions and further developments are given in section 5 .

\section{Road accidents and city sustainability}

\subsection{Road accident impacts}

As said, development must be characterized by the definition of economic, environmental and social sustainability. Although many indicators can be found with different goals and outcomes in the literature, in the field of transport in a compact way, we can consider that economic and social sustainability can be treated, in one of the first instances, in terms of efficiency and safety, and environmental sustainability in terms of air pollution. Even if safety is the new 
incoming challenge for cities, it has received little attention in respect of the environmental counterpart. Then, in the following, the road safety, as a crucial element for the improvement of urban areas and to meet the objectives of city sustainability, will be investigated. Besides, safety impacts on both social (e.g. deaths - human health impacts) and economic (e.g. crash costs) aspects (Table 1) can be led.

Table 1: $\quad$ Transportation impacts on sustainability.

\begin{tabular}{lll}
\hline Economic & Social & Environmental \\
\hline Traffic congestion & Inequity of impacts & Air pollution \\
Mobility barriers & Mobility disadvantaged & Climate change \\
Crash damage & Human health impacts & Habitat loss \\
Transportation facility costs & Community cohesion & Water pollution \\
$\begin{array}{l}\text { Consumer transportation costs } \\
\text { Depletion of non-renewable }\end{array}$ & Community livability & Hydrologic impacts \\
resources & Aesthetics & Noise pollution \\
\hline
\end{tabular}

Source: TDM Encyclopedia [3].

Urban economies are evolving rapidly towards a higher level of material intensiveness. Cities represent multiple dimensions of human activity from economic, social, political and cultural standpoints. Translating the concept of sustainable development to the urban scale requires that inhabitants' needs are met without imposing unsustainable demands on local, as well as on global, natural systems. Indeed no city sustains itself within its own boundaries. However, freight transportation maintains a set of core relationships with urban areas since a city is an entity where production, distribution and consumption activities are located and use limited land. The growing importance of urban freight transport is certainly related to increases in urban populations and continued economic growth in urban areas, too [4]. Besides, the freight transportation contributes to congestion, air pollution, noise and to raise logistic costs, and hence the price of products. In fact, about the $69 \%$ of road accidents occur in cities [5], while the percentage of urban accidents involving shopping and restocking vehicles varies between 5 and $7 \%$.

The road accidents are hence responsible of social and economic costs supported by collectivity due to such events. The economic damage is not represented by a direct charge incurred by the society, but it is the quantification of the economic costs which, in different ways, lay on the collectivity as the consequences caused by a road accidents.

In relation to the sphere of sustainability, the costs due to road accidents can be referred to the accident victim (social) and to the road accident (economic). The former ones refer to human costs, such as cost of human life (lost productivity, non-pecuniary damage - moral and biological) and health care costs (costs of medical treatment); the latter ones are general costs due to the accident, such as property damage (damage to vehicles, buildings, roads and so on) or administrative costs (costs of intervention of the emergency services, litigation costs and administration). In Italy, for example, in 2008, the costs due to road 
accidents (both urban and extra-urban area) were estimated equal to 30.25 billion Euros that represents the $2 \%$ of Italian GDP.

Furthermore, as suggested by some authors [6] within the economic sphere we have to consider other types of costs on transport service system such as delay cost (i.e. total vehicle hours of delay caused by the incident), increased vehicle operating costs (i.e. due to operate in the more congested flow conditions caused by the accidents).

In this context, the local administrators are looking at city logistics measures to limit these types of urban freight impacts, and modelling framework for $e x$ ante assessment have to be used. Usually, the environmental aspects have been more in-depth investigated [7 and references quoted therein].

Finally, in a general urban planning process $[8,9]$ promoted by local administrators, some indicators can be used in order to support the definition of freight planning in terms of outcomes and goals [10]. Within the sphere of sustainability, although the road accidents can also have economic impacts (e.g. crash damages), the social sustainability could be analysed in terms of road accidents and then, some indicators can be used, e.g. number of accidents, number of fatalities, involvement of shopping and restocking vehicles in accidents, and weekly and hourly distribution of accidents involving shopping and restocking vehicles classified for weight. Besides, a key-role in a disaggregate approach is played by road flows (in terms of vehicle type) that should be also characterized in relation to type of users. Although several methods and models have been proposed to obtain the urban flows (related to both passengers and freight), in the following a general modelling framework able to simulate in a joint way passengers and freight movements is recalled.

\subsection{Measures for reducing freight transport impacts}

In urban areas, we meet two conflicting interests both ones addressed to satisfy the user needs:

- end consumers (residents) and public authorities; they want to reduce the transport impacts in order to have an attractive city for inhabitants and visitors (mainly environmental and social sustainability such as reduction of congestion, pollutant, accidents, and so on);

- retailers (producers) and private companies (carriers); they want to delivery and pick-up the goods at the lowest cost but high-quality transport operation and short lead-time in order to satisfy at the best possible way the users' expectations (mainly economic sustainability).

Analysis and selection of implementable measures has to consider such actors (decision-makers) and find an optimal balance between all interests of the involved actors. This is a critical factor in the success of each set of measures, as confirmed in the UK [11-13]. Then, sustainable solutions have to solve the problems in the city centres, and its main goal is the research of solutions that reduce the impacts of urban goods mobility without penalising the life of the city. As it happens in passenger mobility, we can face the problems related to externalities due to transport addressing to transit. It allows us to not reduce 
accessibility and penalise the life of the city. At the same way, we have to investigate the possible solutions that allow us to reduce externalities, to increase sustainability without damaging the city life.

Therefore, to reach the above goals, city administrators implemented different measures that can be classified according to some characteristics useful for their ex-ante assessment. In particular, the different proposed classifications can be synthesized as follows:

- COST 321 [14] has identified 8 classes: logistical measures, modal choice, price of transport, infrastructure and physical planning, traffic management, technical measures concerning the vehicle, measures concerning the way of driving, other measures;

- Munuzuri et al. [15] have proposed 5 classes: public infrastructure, land use management, access conditions, traffic management, enforcement and promotion;

- City Ports [16] promoted 2 classification criteria: what is regulated, how to regulate;

- $\quad$ BESTUFS [17] identifies 3 main fields: goods vehicle access and loading approaches in urban areas, principal issues involved in last mile solutions, principal issues associated with urban consolidation centres (urban distribution centres);

- Van Duin and Quak [18] have identified 3 main areas of attention: flow improvements, hardware, policy;

- Russo and Comi [10] classify in 4 classes in relation to decision-maker, outcomes and goals, planning horizons: material infrastructures, nonmaterial infrastructures, equipment and governance.

\section{Methods of studying road accidents}

The study of accident requires specific accident data analysis in order to obtain the risk factors and the safety performances. Two different methodological analyses can be used [19]: aggregate or disaggregate. In the following each of them is briefly described.

Analysis should be applied to the accidents that occur in an area where the frequency of accidents is higher than the other ones (i.e. black-spots). The blackspots can be relative to a local area (e.g. junction) or a large area (e.g. road network). Their identification derives from predefined accident aggregate indicators.

The aggregate analysis concerns a large area (such as an urban area or a central business district) and estimates the probability of an accident occurring in relation to a set of attributes that generally are macro. With aggregate analysis, the accident data are studied to define the accident problem level as well as to locate the black-spots and define strategies and measures.

The quantification (frequency) and characterization of accidents is based on available data obtained from Institutional Agencies (e.g. Italian National Institute of Statistics, EuroStat). This type of analysis allows us to estimate the number of accidents in an extended area or in relation to particular type of accidents. In the 
former, the infrastructural black-spots can be identified, while in the latter it is possible to estimate the weight of accident classes in relation to total number of accidents. Therefore, some indicators can be used in order to identify risk behaviour of users due to no-use of safety passive devices (e.g. seat belts), nocompliance of Highway Code.

The identification of black-spots can be done through the spatialization of different indicators. Examples of possible indicators to be used in an aggregate accident analysis can be classified as follows:

- general data, e.g. dimension of study area, inhabitants also aggregated for age classes, type of city (touristic, industrial) or type of area (e.g. cbd);

- data on mobility, e.g. network length also classified for type, road flows, pedestrian network length, characteristics of transit, number of veh-km per class of vehicles;

- data on accidents and involved users, i.e. total number of accidents per reference time, total number of deaths, number of injured, characteristics of involved users (e.g. age, sex), day of the week, type of vehicle, type of accident (e.g. lateral or frontal crash)

The analysis of these types of data can be done in order to obtain the absolute or the percentage values. The absolute values give us the dimension of phenomenon, in space and time. The percentages allow to identify the relevant characteristics of accidents (e.g. number of deaths respect to the total number of accidents), to verify the incidence of environmental factors (e.g. type of involved vehicles). The analysis of these values also provides indication for the existence of black-spots and for comparing different areas.

The disaggregate analysis concerns an infrastructural element (such as a road, junction, or parking area) and defines common elements in the accidents in order to identify safety measures to avoid impacts in relation to a set of attributes that are generally micro. With disaggregate analysis the accident scenario can be generated. For disaggregate analysis, different methods have been proposed that can be classified in Russo and Vitetta [19]: collision diagram, cinematic reconstruction, accident scenario.

For example, the collision diagram [20] is a schematic representation of accidents occurred in a specific place and time. Then, they are drawn with schematic conventional signs (segments, lines, circles). Each conventional sign represents a kind of accident or a kind of collision and each accident is defined with the drawing. All the data relative to the accidents are reported and classified in a table in order to select the factors that have produced the accidents. This type of method synthesizes the major information referring to the accident, such as type and severity of accident, date and time, road conditions and so on.

\section{The network road flows for safety analysis}

In order to evaluate the performance of road network in terms of safety, a key role is played by simulation models. A large literature exists on passenger mobility but fewer studies have been done on freight/goods mobility, and, in particular, on joint analyses. In fact, the literature review [21-24] shows that 
many urban freight models are not integrated with the models that simulate other components of urban mobility and many of them are only theoretical: they are not used (or usable) for forecasting the impacts of implementing traffic and transportation measures at an urban scale. These models have been developed to simulate some aspects of the restocking process and do not start from the end consumer. Hence, it is difficult to consider the link between these urban models (developed mainly for logistic trips) and end-consumer models (which are those developed for passenger mobility) and to analyse the complexity of urban transport systems with all the components that make up urban mobility. Then, there are models proposing to integrate the previous types of models in a general framework, representing commodity flows as generated by the consumption of the commodity, as a component of the generic urban activity undertaken by consumers. The main characteristic of this general framework is the representation of interacting behaviour of commodity consumers and commodity suppliers/shippers/retailers [25, 26].

Referring to the general modelling system developed by authors [27] consisting of two levels for a medium-size city, it applies a disaggregated approach for each decision level (Figure 1):

- commodity level (first level) concerning estimation of the quantity of Origin-Destination (O-D) flows; at this level the models involve the calculation of

O O-D flows related to consumption and, then, the endconsumers' behaviour is investigated and simulated in terms of characteristics of undertaken journey (e.g. origin and destination, dimension of purchases, mode; [28]);

o O-D freight flows related to restocking and then to simulate the restocking process of retail activities located within the urban and metropolitan area (study area) in terms of distribution channels (i.e. to pull or push movements) and the destination areas where freight is to be sold in retail outlets (inside or outside study area);

- vehicle level (second level) that allows quantity flows to be converted to vehicle flows [29, 30]; at this level the models involve the determination of

o restocking trip chain in terms of the quantity brought to each stop, the zone and vehicles needed for restocking;

- time as well as the path chosen for restocking sales outlets.

The structure of the models in question [27] may be updated or developed with other models from the literature, referring to the behavioural aspect underlined in Russo [23]. First, the structure may be developed by explicitly introducing the vehicle level component for the end consumer. In this way the second level concerns not only the vehicles used in the restocking process, but also those used in shopping processes. For vehicles involved in shopping processes, the macro-models are those of mode and path choice with assignment. The complete structure could endogenize the push/pull dichotomy. 


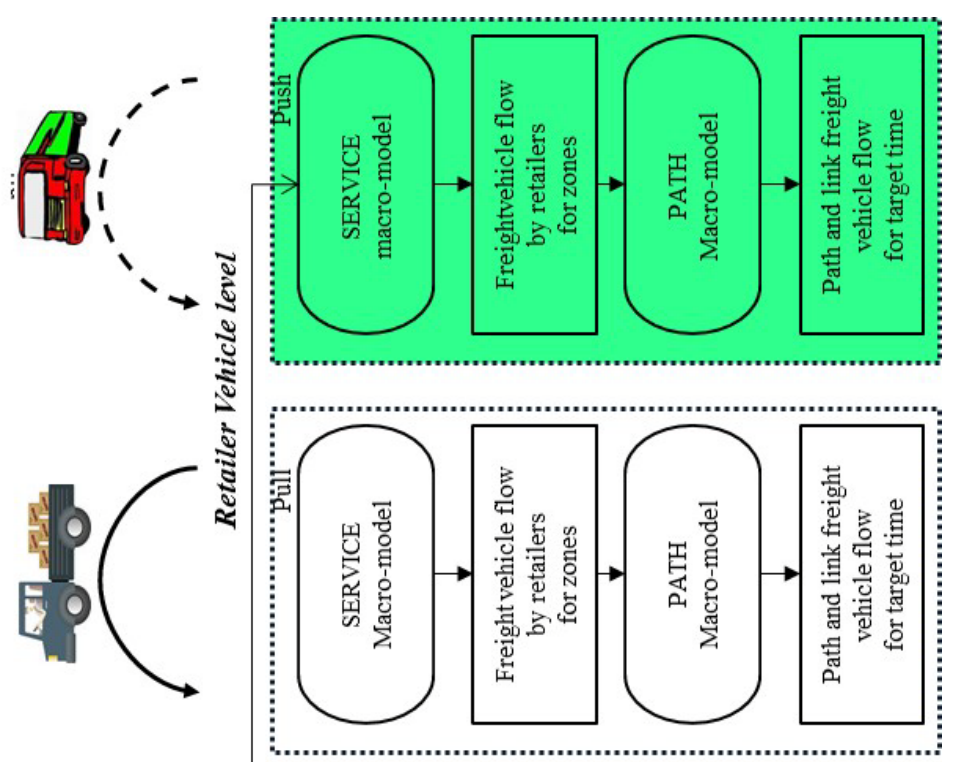

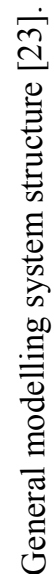
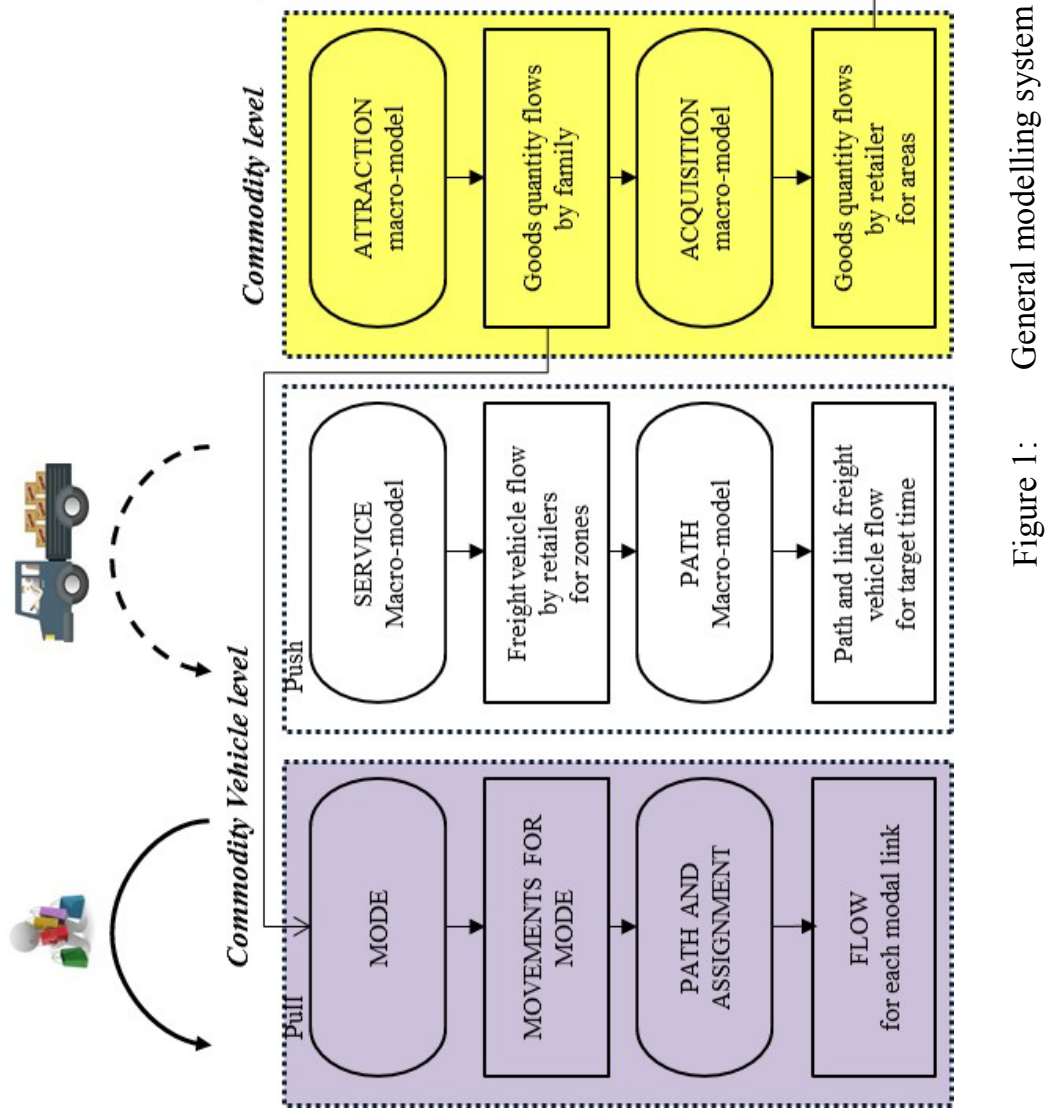
In the last years, the population concentrations in urban areas and changes in the social structure, combined with the need for sustainable mobility, heighten problems connected to the purchasing of goods by the end user and the restocking of retail outlets. Trips for purchases are, in percentage terms, ever closer to those of home-work (commuting), exceeding in urban areas systematic home-work trips. In the US in 1983 the average annual person trips per household amounted to 537 to/from work and 474 for shopping. By 2009 this had changed to 541 to/from work and 725 for shopping [31]. The traditional structure of restocking of neighbourhood shops, and hence of buying consumer goods in such shops, is being increasingly modified by new forms of purchase and distribution, resulting from the Internet. In the US, e-commerce sales in 2010 increased by $14 \%$ against 2009 [32]. End users have modified their behaviour and purchasing decisions over time, gradually switching from traditional distribution channels.

In this context, within the field of social sustainability the analysis of road accidents becomes very important and has to be studied considering shopping and restocking vehicles, jointly. Then, although the number of accidents has fallen, those within urban areas are more than $60 \%$ for some European countries and it is remained quite constant along the last decades (Figure 2). Therefore, the local administrators have to point out the problems and promote different types of actions in order to improve the sustainability and liveability of cities. In fact, we can see countries (e.g. Germany) that are reducing the total number of road accidents but the urban percentages are increasing, and countries (e.g. Italy) that have high percentages of urban accidents.

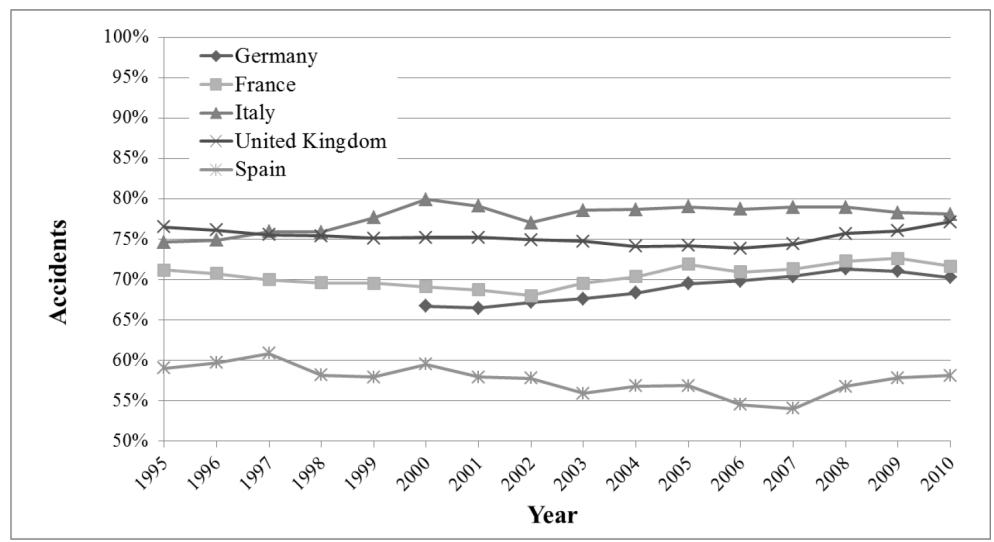

Figure 2: National trend of percentages of urban road accidents in some European countries (elaboration based on data from CARE [33]). 


\section{Conclusions}

The paper, within the field of city sustainability, recalled the methods to analyse the road accidents and recalls an integrated modelling framework for disaggregate analysis of road accidents. In fact, the paper is based on the statements that urban mobility structure in the last decades is changed and the shopping trips are becoming preponderant respect to commuting ones. Therefore, the analysis of city sustainability can not neglect them. Besides, we have to note that restocking vehicles flows are strictly related to end consumer trips. In fact, the restocking flows are produced in order support a given end-consumer need. Ignoring these interactions is obviously inappropriate, because traffic impact is an effect shared and generated by both markets, and presumably the decisionmakers take the effect into consideration before making a transportation decision. Urban policy-makers involved in designing urban measures have to deal with a large number of trucks and vans delivering goods in the urban area whilst preserving the economic viability of city businesses and also ensuring social sustainability. This study pointed out the importance of new approach in analysing road accident on the urban networks and gives the line for the future developments. In particular, aggregate and disaggregated models for the analysis of road accidents involving goods vehicles at urban level are being developed.

\section{References}

[1] WCED (1987) Our Common Future - Chapter 2: Toward sustainable development. World Commission on Environment and Development A/42/427.

[2] Gonzalez-Feliu, J., Ambrosini, C., Pluvinet, P., Toilier, F. and Routhier, J. L. (2012) A simulation framework for evaluating the impacts of urban goods transport in terms of road occupancy. In: Journal of Computational Science 3 (4), Elsevier, 206 - 215.

[3] TDM Encyclopedia (2010). Sustainable Transportation and TDM. Victoria Transport Policy Institute, www.vtpi.org.

[4] Browne. M. Allen. J. Nemoto, T., Patier, D. and Visser, J. (2012) Reducing social and environmental impacts of urban freight transport: A review of some major cities. In: Procedia - Social and Behavioral Sciences 39, Elsevier Ltd, $19-33$.

[5] White Paper (2011) Roadmap to a Single European Transport Area Towards a competitive and resource efficient transport system, European Commission, Brussels.

[6] Ogden, K. W. (1992) Urban Goods Movement. Ashgate, Hants, England.

[7] Russo, F. and Comi, A. (2012) City Characteristics and Urban Goods Movements: A Way to Environmental Transportation System in a Sustainable City. In: Procedia - Social and Behavioral Sciences 39, E. Taniguchi and R. G. Thompson (eds.), DOI: 10.1016/j.sbspro.2012.03.091, Elsevier Ltd, 61-73. 
[8] NORAD (1999) Logical Framework Approach: handbook for objectivesoriented planning. Norwegian Agency for Development Cooperation, Norway.

[9] Russo, F. and Rindone, C. (2011) The planning process and logical framework approach in road evacuation: a coherent vision. In: WIT Transactions on the Built Environment, Vol. 117. WITpress, Southampton, U.K.

[10] Russo, F. and Comi, A. (2011) Measures for sustainable freight transportation at urban scale: expected goals and tested results in Europe. In: Journal of Urban Planning and Development 137 (2), DOI: 10.1061/(ASCE)UP.1943-5444.0000052, American Society of Civil Engineers (ASCE), 142-152.

[11] DfT (2003) A Guide on How to Set Up and Run Freight Quality Partnerships. Good Practice Guide 335, Department of Transport, United Kingdom.

[12] Dablanc, L. (2007) Goods transport in large European cities: Difficult to organize, difficult to modernize. In Transportation Research Part A 41, Elsevier.

[13] Stathopoulos, A., Valeri, E., Marcucci, E., Nuzzolo, A. and Comi, A. (2011) Urban freight policy innovation for Rome's LTZ: a stakeholder perspective. In City distribution and urban freight transport: multiple perspectives, Melo, S. and Macharis, C. (eds.), Edward Elgar Publishing, Cheltenham, U.K.

[14] COST 321 (1998) Urban goods transport, Final report of the action. Transport Research, European Commission Directorate General Transport, Belgium.

[15] Muñuzuri, J, Larraneta, J., Onieva, L. and Cortés, P. (2005) Solutions applicable by local administrations for urban logistics improvement. In: Cities 22 (1), Elsevier.

[16] City Ports (2005) City Ports - project interim report. Emilia-Romagna, Bologna, Italy.

[17] BESTUFS (2007) BESTUFS - Good Practice Guide on Urban Freight. BESTUFS Consortium, www.bestufs.net.

[18] Van Duin, J. H. R. and Quak, H. J. (2007) City logistics: a chaos between research and policy making? A review. C. Brebbia (ed), Urban Transport and the Environment in the 21st Century, WitPress.

[19] Russo, F. and Vitetta, A. (2003) Disaggregate road accident analysis for safety policy and measures: theoretical aspects and application. In: Proceedings of the European Transport Conference (PTRC), Strasbourg, France.

[20] Litvin, D. M., Datta, T. K. (1979) Automated collision diagrams. In: Transportation Research Record 706, Washington, DC, USA.

[21] De Jong, G., Vierth, I., Tavasszy, L. and Ben-Akiva, M. (2012) Recent developments in national and international freight transport models within Europe. In: Transportation 40 (2), Springer, 347 - 371. 
[22] Russo, F. and Musolino, G. (2012) A unifying modelling framework to simulate the Spatial Economic Transport Interaction process at urban and national scales. In: Journal of Transport Geography 24, Elsevier, 189-197.

[23] Russo, F. (2013) Modelling behavioral aspects of urban freight movement. In: Freight Transport Modelling, Ben-Akiva, M., Meersman, H. and Van de Voorde, E. (eds.), Emerald Group Publishing Limited, Bingley, U.K.

[24] Nuzzolo, A., Coppola, P. and Comi, A. (2013) Freight transport modeling: review and future challenges. In: International Journal of Transport Economics Vol. XL No. 2, June 2013, Serra, Rome.

[25] Oppenheim, N. (1993) A combined, equilibrium model of urban personal travel and goods movements. In: Transportation Science 27 (2), 161-173.

[26] Comi, A. and Nuzzolo, A. (2013) Comi, A. and Nuzzolo, A. (2013). Simulating urban freight flows with combined shopping and restocking demand models. In: Procedia - Social and Behavioral Sciences, Proceedings of the $8^{\text {th }}$ International Conference on City Logistics, E. Taniguchi and R. G. Thompson (eds.), Elsevier Ltd.

[27] Russo, F. and Comi, A. (2010) A modelling system to simulate goods movements at an urban scale. In: Transportation 37 (6), DOI: 10.1007/s11116-010-9276-y, Springer Science+Business Media, LLC: $987-$ 1009.

[28] Russo, F. and Comi, A. (2012) The Simulation of Shopping Trips at Urban Scale: Attraction Macro-Model. In Procedia - Social and Behavioral Sciences 39, E. Taniguchi and R. G. Thompson (eds.), DOI: 10.1016/j.sbspro.2012.03.116, Elsevier Ltd, 387-399.

[29] Polimeni, A. and Vitetta, A. (2013) A comparison of vehicle routing approaches with link costs variability: An application for a city logistic plan. In: WIT Transactions on the Built Environment, vol. 130, 823 - 834.

[30] Russo, F., Vitetta, A. and Polimeni, A. (2010) From single path to vehicle routing: the retailer delivery approach. In: Procedia - Social and Behavioral Sciences 2(3), E. Taniguchi and R. G. Thompson (eds.), Elsevier Ltd.

[31] NHTS (2009) National Household Travel Survey Average Annual PMT (Person Miles of Travel), Person Trips and Trip Length by Trip Purpose. Table 5.

[32] Census, 2011. Estimated quarterly US Retail Sales: Total and e-commerce. Table 1.

[33] CARE (2012) European centralised database on road accidents which result in death or injury across the EU. Road Safety Programme, European Commission, Brussels. 